Sustainability indicators for biobased chemicals: A Delphi study using Multi- Criteria Decision Analysis

Peer-reviewed author version

VAN SCHOUBROECK, Sophie; SPRINGAEL, Johan; VAN DAEL, Miet; MALINA, Robert \& VAN PASSEL, Steven (2019) Sustainability indicators for biobased chemicals: A Delphi study using Multi- Criteria Decision Analysis. In: Resources, conservation and recycling, 144, p. 198-208.

DOI: $10.1016 / j . r e s c o n r e c .2018 .12 .024$

Handle: http://hdl.handle.net/1942/27927 


\title{
SUSTAINABILITY INDICATORS FOR BIOBASED CHEMICALS: A DELPHI STUDY USING MULTI-CRITERIA DECISION ANALYSIS
}

\author{
Sophie Van Schoubroeck* \\ UHasselt - Hasselt University, Centre for Environmental Sciences, Agoralaan, 3590 Diepenbeek, Belgium \\ Unit Separation and Conversion Technologies, VITO, Boeretang 200, $2400 \mathrm{Mol}$, Belgium \\ University of Antwerp, Department of Engineering Management, Prinsstraat 13, 2000 Antwerpen, Belgium \\ e-mail: sophie.vanschoubroeck@uhasselt.be \\ Johan Springael \\ University of Antwerp, Department of Engineering Management, Prinsstraat 13, 2000 Antwerpen, Belgium \\ Miet Van Dael \\ Unit Separation and Conversion Technologies, VITO, Boeretang 200, $2400 \mathrm{Mol}$, Belgium \\ UHasselt - Hasselt University, Centre for Environmental Sciences, Agoralaan, 3590 Diepenbeek, Belgium \\ Robert Malina \\ UHasselt - Hasselt University, Centre for Environmental Sciences, Agoralaan, 3590 Diepenbeek, Belgium \\ Steven Van Passel \\ UHasselt - Hasselt University, Centre for Environmental Sciences, Agoralaan, 3590 Diepenbeek, Belgium \\ University of Antwerp, Department of Engineering Management, Prinsstraat 13, 2000 Antwerpen, Belgium
}

\begin{abstract}
Biobased chemistry has gained interest and has the potential to tackle some of the sustainability challenges the chemical industry must endure. Sustainability impacts need to be evaluated and monitored to highlight the advantages and pitfalls of different biobased routes over the entire product life cycle. This study aims for expert consensus concerning indicators needed and preferred for sustainability analysis of biobased chemicals in Europe. Experts are consulted by means of a Delphi method with stakeholders selected from three core groups: the private, public and academic sector. Best-Worst Scaling (BWS) is performed to gather data on the prioritization of the sustainability indicators per respondent. Afterwards, Multi-Criteria Decision Analysis (MCDA) is used to develop a consensus ranking among the experts. The results show that GHG emissions, market potential and acceptance of biobased materials are deemed the most crucial indicators for respectively environmental, economic and social sustainability. Expert consensus is positive in all three sustainability domains, with the strongest consensus measured for environmental sustainability showing a median Kendall's $\tau$ of 0.63 ( $\tau$ ranging from -1 to 1 ) and the weakest consensus found within social sustainability showing a median Kendall's $\tau$ of 0.50 . Further research can apply the ranked indicators on specific case studies to evaluate the practicability of the defined indicator set.
\end{abstract}

KEYWORDS Biobased chemicals - Sustainability indicators - Indicator selection - Delphi study Best-Worst Scaling - Multi-Criteria Decision Analysis

\footnotetext{
${ }^{*}$ Corresponding author
} 


\section{INTRODUCTION}

As population is growing and fossil resources are shrinking, more attention is paid to building and maintaining a sustainable global economy. The desire of countries to reduce fossil fuel import dependency, stimulate regional and rural development, mitigate climate change, and promote circularity, has driven the 'start' of the transition towards a biobased economy (Chiu et al., 2018; Jong et al., 2011; Ranta et al., 2018). However, this transition to an economy based on renewable resources is expected to have many setbacks and obstacles on a technical and political level (Philp, 2017). A biobased economy does not guarantee an increase of environmental, economic and social sustainability. While biobased technologies and products can potentially decrease greenhouse gas emissions (GHG) and reduce ecotoxicity, it can also trigger adverse effects like e.g. land use change (LUC), soil degradation and pollution of water resources (Gawel and Ludwig, 2011; Pursula et al., 2018). It is important to assess these sustainability impacts of biobased products and steer technologies towards sustainable development, while still being at a low Technology-Readiness Level (TRL).

Many definitions and assumptions about the concept of 'sustainability' do exist. A well-known definition introduced by the World Commission on Environment and Development (WCED) is: "sustainable development is development that meets the needs of the present without compromising the ability of future generations to meet their own needs" (WCED, 1987). With this statement from the famous 'Brundtland Report', the WCED popularised 'Sustainable Development' and organizations increasingly adopted a strategy to move towards sustainability (Carter, 2018). However, putting this definition into practice has been a challenge for decades as it leaves room for many interpretations (Bennich and Belyazid, 2017). As a result, practitioners of sustainability analysis currently use different sustainability indicators which leads to a lack of harmonization (Philp, 2017).

Sustainability analysis often includes a (Social) Life Cycle Assessment (SLCA) or Techno-Economic Assessment (TEA), which are methods used to evaluate technologies and products (Hoogmartens et al., 2014). An evaluation of the entire product life cycle is recommended to accommodate a wider perspective on biobased sustainability. Within the biobased economy, SLCA and TEA are most often developed for biofuels and bioenergy (Fritsche and Iriarte, 2014). However, biobased chemicals can potentially be sold at a higher selling price which creates more opportunities within the biobased and chemical industries (Fritsche and Iriarte, 2014; Wu et al., 2018). Within the European bioeconomy, the highest levels of labor productivity were achieved in the manufacturing of biobased chemicals, pharmaceuticals, plastics and rubber (Ronzon et al., 2017). Biobased chemicals are chemicals which are at least partially derived from biomass, such as plants, trees or animals, with the biomass potentially undergoing physical, chemical or biological treatment (European Committee for standardization, 2014). The corresponding biobased feedstock encompasses agricultural crops, dedicated energy crops and trees, agriculture and forestry residues, aquatic plants, and animal and municipal waste (Sheldon, 2011). A large amount of chemicals can be produced from biomass like many platform chemicals, amino acids, vitamins, polymers and industrial enzymes (Philp et al., 2013).

Next to economic opportunities, there is also an environmental justification to explore the market of biobased chemicals. The introduction of biobased chemistry can potentially reduce the number of toxic chemicals being produced and so benefit human and environmental health. The production of chemicals in the European Union reached 319.5 million tonnes in 2016, with approximately $63 \%$ of these chemicals being hazardous to human health (Eurostat, 2017a). The implementation of stringent regulatory frameworks, like REACH (Registration, Evaluation and Authorization of Chemicals) and RoHS (Restriction on Hazardous Substances), has driven the industry to look for less toxic substitutes, including biobased chemicals. Other potential sustainability benefits include the reduction of greenhouse gas emissions, biodegradability, employment opportunities, local production, etc. A 
thorough sustainability analysis and comparison with the fossil-based counterpart is necessary to draw proper conclusions and invest in the most sustainable alternative. The entire product life cycle of a biobased chemical should be taken into account in such an analysis to correctly estimate the sustainability impacts of technologies and products. Figure 1 shows the simplified life cycle of a biobased chemical from raw material extraction to possible end-of-life options.

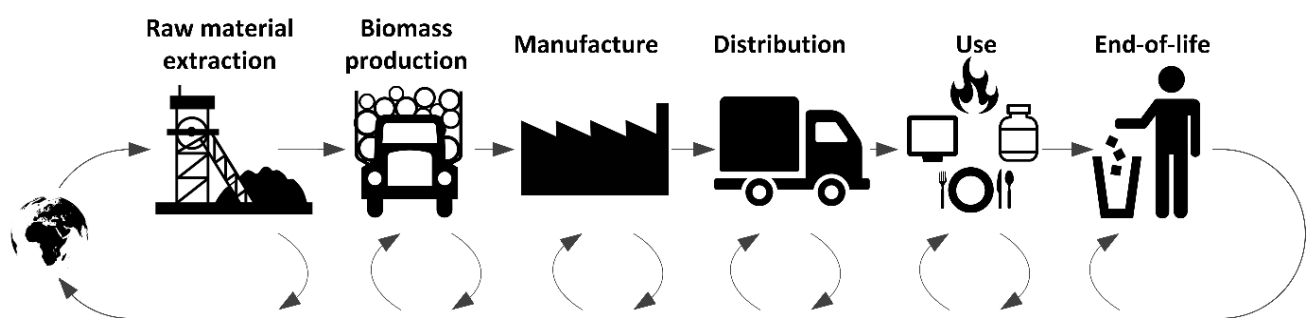

Figure 1. Total life cycle of a biobased product (Thomassen, 2018)

An in-depth analysis on the criteria, indicators and remaining gaps within sustainability evaluations of biobased chemicals was done in Van Schoubroeck et al. (2018). The review shows that a complete and comprehensive indicator framework for the evaluation of sustainable biobased chemicals does not exist. The existing indicator sets are often incomplete, lack an holistic view on sustainability and require more focus on the applicability for biobased chemicals (Van Schoubroeck et al., 2018). There is a lack of inclusion of social and economic impact categories and most assessments stay onedimensional using a limited set of environmental indicators (Philp, 2017; Van Schoubroeck et al., 2018).

This study will be the first to develop a complete and balanced set of indicators to perform sustainability evaluation, specifically for biobased chemicals. A consensus ranking can lay the foundation for the harmonization of sustainability analysis within the field of biochemistry. Industrial, governmental and academic stakeholders will be able to identify promising and emerging products and factor in sustainability considerations for funding and procurement decisions. By assessing environmental, as well as social and economic aspects, sustainability barriers can be identified and addressed starting from a low TRL. This shortens time-to-market of new sustainable biobased products and facilitates their implementation. Entailing this full sustainability analysis enables industries and policy makers to bring sustainable biobased chemicals to the society and foster the biobased economy as a whole. Furthermore, this study contributes to the development of a mixedmethod using qualitative (i.e. Delphi) and quantitative (i.e. MCDA) tools, which can deal with many attributes (i.e. sustainability indicators) in an ordinal way.

The paper is structured as follows: section 2 provides an overview of the different research steps and methods. In section 3 the research outcomes are quantitatively described, compared and a final consensus sustainability ranking is proposed. Section 4 further discusses the results and limitations of this study, and provides suggestions for future research. Section 5 concludes the paper.

\section{METHOD}

The research goal requires a methodological approach which (1) collects and interprets information about sustainability indicators on the one hand, and (2) ranks the indicators based on their relevance on the other hand. Therefore, a Delphi study was combined with a Multi-Criteria Decision Analysis (MCDA) to fully address the research question. Previous research at the Engineer Research and Development Center (ERDC) shows that the combination of these methods can resolve research designs which involve decision-making under situations of high complexity and uncertainty (De Carvalho et al., 2017; B. Trump et al., 2018; B. D. Trump et al., 2018). A Delphi survey is an iterative group facilitation methodology, designed to transform opinion into group consensus (Hasson et al., 
2000). The Delphi method is pooling the talents of experts to reach consensus based on structured feedback (Chang et al., 2000). Using group feedback from the previous round, the researcher develops a next round of questions for the respondents (Okoli and Pawlowski, 2004). Delphi techniques are useful for indicator selection of complex sustainability issues (Benitez-Capistros et al., 2014; Hai et al., 2014; Mapar et al., 2017). This qualitative survey method contributes to a higher efficiency of quantitative techniques such as MCDA (De Carvalho et al., 2017; Kendall, 1970). A combination of Delphi and MCDA is already widely applied in the topic of sustainability (Chiu et al., 2018; De Feo et al., 2018; Zhao and Li, 2016).

In this study, a two-round Delphi survey is conducted with an open and closed question round to select and prioritize sustainability indicators for the evaluation of biobased chemicals. The questionnaires were created in Qualtrics Software (C 2018 Qualtrics ${ }^{\circledR}$ ) and distributed by e-mail to experts. A full version of the questionnaire can be provided by the authors upon request. Participants were selected based on their expertise in sustainability and biobased chemistry. The experts are divided into the following three core groups: private sector (industrial companies), public sector (administrations, certification and labelling bodies and non-governmental organizations) and academic sector (universities and research institutes). Literature recommends at least 10 experts, which are anonymous to each other, for a Delphi panel to be able to reach consensus based on group dynamics (Okoli and Pawlowski, 2004). In total, 246 potential experts in Europe were contacted for this study.

\subsection{First Delphi round}

In the first Delphi round, open questions are asked to brainstorm and gather data for the creation of a list of sustainability indicators. In total, the responses of 71 experts are included for analysis (response rate: $29 \%$ ), with $39.44 \%$ of the experts working in industry, $39.44 \%$ of the experts working in academics and $21.13 \%$ of the experts working in the public sector. The respondents are located in twelve different countries in Europe, most of which holding a doctoral degree (64.99\%). The experts' answers are analysed by open coding, using the NVivo software for qualitative data analysis (NVivo, 2015; Strauss and Corbin, 1998). Open coding is defined as the "analytical process through which concepts are identified and their properties and dimensions are discovered in the data" (Strauss and Corbin, 1998). The outcome of this qualitative analysis was merged with the results of a literature review performed by Van Schoubroeck et al. in 2018 and resulted in a comprehensive list of indicators which was used as input for the second Delphi round.

\subsection{Second Delphi round}

"The objective of MCDA is the study of decision problems in which several points of view must be taken into consideration" (Roy and Vincke, 1981). As the decision problem in this particular study entails more than nine attributes (i.e. indicators) per sustainability dimension, the use of certain MCDA methods, such as AHP (i.e. Analytic Hierarchy Process) or MACBETH (Measuring Attractiveness by a Categorical Based Evaluation Technique) are not appropriate for this study (Bana e Costa and Chagas, 2004; Saaty and Ozdemir, 2003). Data collection is time consuming and complex when many attributes are involved, and the selection of an appropriate MCDA has to be adapted to this specific multiattribute situation. The utilization of Best-Worst Scaling (BWS) exercises was therefore selected as a fitting data collection method for the second Delphi round. Finn and Louviere introduced BWS in 1992 as an alternative for the use of rating scales in questionnaires (Flynn and Marley, 2014). BWS is a costefficient way of obtaining more information from the experts (Finn and Louviere, 1992; Flynn and Marley, 2014). BWS provokes discrimination and avoids using a rating scale by asking the experts to indicate the 'best' and 'worst' item from a set of attributes (Lee et al., 2008). In this study, the BWS method is used to measure the preference scores from a list of sustainability indicators by using experts opinion. Afterwards the survey data is used to compose a ranking per respondent, which 
provides the input needed to perform a specific MCDA approach called AURORA (i.e. aggregating unicriterion rankings into one ranking) (De Keyser and Springael, 2009). The AURORA method merges and compares the experts' rankings, respecting the ordinal character (De Keyser and Springael, 2009; Keune et al., 2013).

Sawtooth's SSI Web platform (๔ 2018 Sawtooth Software ${ }^{\circledR}$ ) is used to build Balanced Incomplete Block Designs (BIBD) for the BWS exercise. Three different questionnaire versions were created, each containing three separate block designs for the environmental, social and economic aspects of sustainability. Every questionnaire design contains 25 questions with 6 attributes shown per question. The design algorithm is comparable with those of a Choice Based Conjoint (CBC) and is created based on one- and two-way frequencies, positional balance and connectivity (Sawtooth Software, 2013). The three questionnaire versions are assigned randomly to the different respondents. In total, 47 respondents filled out the 25 BWS exercises. Only the experts that responded to the first Delphi survey were contacted again for the second Delphi round (response rate: $66 \%$ ).

The Hierarchical Bayes (HB) method from Sawtooth Software is used to estimate the preference scores for each respondent. HB is a "data borrowing" technique, stabilizing part-worth estimates for each individual by means of borrowing information from other respondents within the same data set (Orme and Baker, 2000). Potential rankings are developed by applying three different methods to compare and improve potential rankings: (1) HB average ranking, (2) HB frequency ranking and (3) HB AURORA ranking. The first two methods, average ranking and frequency ranking, can be conducted using the Sawtooth Software. Afterwards, a specific Branch-and-Bound algorithm is written in C++ to apply the MCDA-method, AURORA. AURORA requires pairwise comparisons between the respondents and a ranking of the alternatives per respondent. Based on the HB preference scores, a ranking per respondent is first computed. The higher the preference score of a respondent for a certain indicator, the higher the ranking position for that indicator. The rank correlation coefficient of Kendall, referred to as Kendall's $\tau$, is used to measure how well a candidate consensus ranking fits a respondent's ranking (De Keyser and Springael, 2009; Kendall, 1938).

$$
\begin{gathered}
\text { Kendall's } \tau=\frac{2 *(C-D)}{n^{2}-n} \text { where } C+D=\frac{n^{2}-n}{2} \\
\text { with } \mathrm{C}=\text { Concordant pairs and } \mathrm{D}=\text { Discordant pairs }
\end{gathered}
$$

The value of Kendall's $\tau$ ranges from -1 to 1 , from perfect disagreement to perfect agreement. The median of these correlation coefficients is determined after every iteration and maximized over the set of potential consensus rankings. In Appendix A the pseudocode of the operating principle is provided. The flowchart of the research steps, including the HB AURORA ranking is shown in Figure 2.

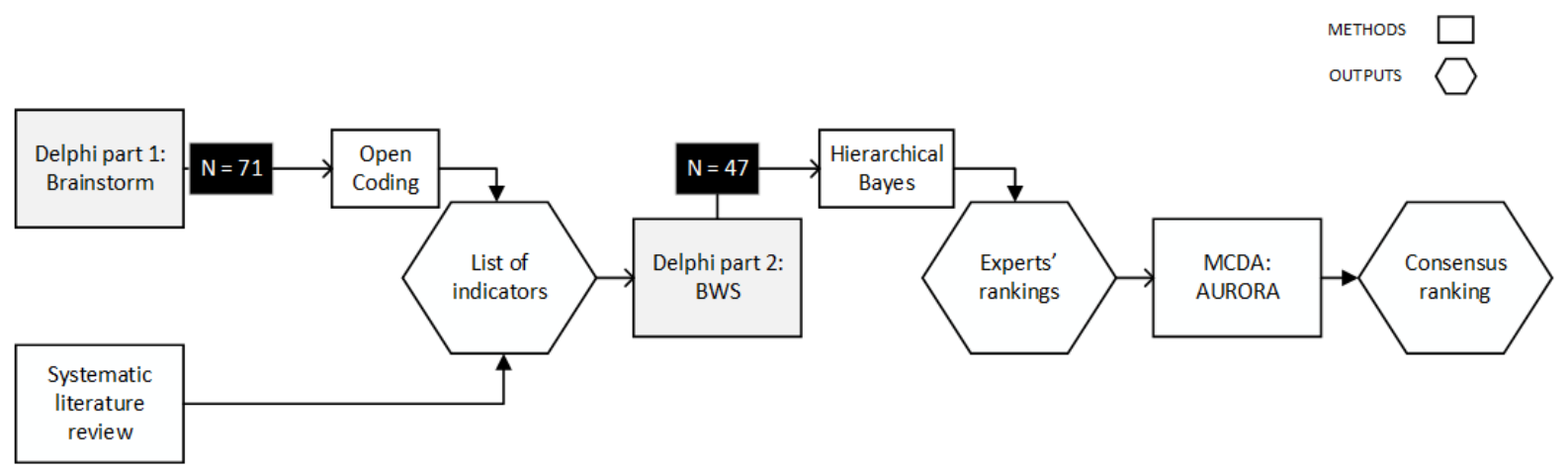

Figure 2. Flowchart research steps (mixed Delphi-MCDA method) 


\section{RESULTS}

Table 1 represents the outcome of the first Delphi round, created by combining open coding and literature review. In total, 20 environmental attributes, 13 economic attributes and 15 social attributes were selected for further analysis in a second Delphi round. A brief description of these indicators, also provided to the experts in the second questionnaire round, is included in Appendix B.

Furthermore, in the first Delphi round, the respondents were asked which evaluation tool they preferred to measure sustainability of biobased chemicals: 'a single index', 'multiple indicators' or 'both'. The results of this survey indicate that 56 experts prefer multiple indicators, 14 choose both and only 1 prefers a single index. The experts in favour of multiple indicators point out that sustainability is too complex to summarize in one index. Providing a scoreboard with multiple indicators allows for more transparency and visualisation of the trade-offs between different sustainability impacts. Aggregation and weighing may mask those trade-offs and present an oversimplification of reality. The reason why some experts have chosen 'both', is mostly due to the communication aspect of an index. It allows easy communication with non-experts, providing a good foundation for first ranking and selection. However, most experts indicate that the index has to be accompanied by separate scores for different stand-alone indicators. A single index allows for direct comparison between biobased alternatives, but similar index-scores might be calculated even when products differ on specific sustainability aspects.

\begin{tabular}{|c|c|c|}
\hline ENVIRONMENT & ECONOMY & SOCIETY \\
\hline Abiotic fossil depletion & Capital productivity & Acceptance of biobased chemicals \\
\hline Abiotic mineral depletion & Energy cost & Child labor \\
\hline Acidification & Labor productivity & Community support and involvement \\
\hline Agricultural land occupation & Land productivity & Cultural heritage \\
\hline Ecotoxicity & Market potential & Discrimination \\
\hline End of life options & Process innovation & Education and training \\
\hline Energy efficiency & Product efficiency & Fatal work injuries \\
\hline Eutrophication & Product innovation & Human toxicity \\
\hline GHG emissions & Raw materials cost & Income levels \\
\hline lonising radiation & Subsidies & Job creation \\
\hline Management practices in crop production & Technical risks & Product transparency \\
\hline Natural land transformation & Transportation cost & Security measures \\
\hline Organic carbon depletion & Waste disposal cost & Social security \\
\hline Particular matter formation & & Working hours \\
\hline photo-oxidant formation & & Workplace accidents and illnesses \\
\hline \multicolumn{3}{|l|}{ Raw material efficiency } \\
\hline \multicolumn{3}{|l|}{ Soil erosion } \\
\hline \multicolumn{3}{|l|}{ Stratospheric ozone depletion } \\
\hline Waste generation & & \\
\hline
\end{tabular}

Table 1. Sustainability indicators for assessment of biobased chemicals

In the second Delphi round, responses of the BWS exercises were analysed using Hierarchical Bayes with all of the experts reaching a fit-statistic, a Root Likelihood, higher than a minimum of 0.167 (Sawtooth Software, 2009). Tables 2-4 show the results of the analysis of the BWS data. The fifth and the sixth column entail a counting analysis, showing the proportion an indicator is picked as best and/or worst. Some attributes are never picked 'best' like photo-oxidant formation, ionising radiation and cultural heritage. lonising radiation has the highest consistency in answers with $60 \%$ of the experts indicating it as 'least important'.

The fourth column shows the average rescaled utility scores (i.e. preference scores) per sustainability indicator. High importance is given to GHG emissions, with an average utility score of 14.40 , followed by raw material efficiency with 10.27 and end of life options with 10.04. Low importance is given to ionising radiation and photo-oxidant formation with average scores of 0.18 and 0.35 . Overall, the 
average utility scores of the environmental attributes decrease more gradually compared to the economic and social dimension. For the economic dimension a stable middle section is noticed with utility scores between 8.98 and 8.20 for the attributes process innovation, product innovation, energy cost, technical risks, land productivity and capital productivity. The highest utility scores are assigned to market potential and raw materials cost with 18.41 and 15.57. For the social attributes, the indicators having the highest importance are human toxicity, product transparency, job creation and acceptance of biobased materials. According to the experts, these four attributes together account for $51.11 \%$ of the total importance in social sustainability. In Appendix C, the distribution of the average rescaled utility scores per dimension are shown.

The second column displays the results of the HB average ranking (i.e. the first ranking method), enclosing a ranking based on the average utilities per indicator with the attributes GHG emissions, market potential and human toxicity ranked first for respectively the environmental, economic and social dimension. lonising radiation, waste disposal cost and cultural heritage are ranked last. However, these average utility scores, used to create the average ranking, should be handled with care as they are affected by extreme values.

\begin{tabular}{|c|c|c|c|c|c|}
\hline \multirow[t]{2}{*}{ Indicator } & \multicolumn{3}{|c|}{ Hierarchical Bayes analysis } & \multicolumn{2}{|c|}{ Counting analysis } \\
\hline & $\begin{array}{l}\text { Average } \\
\text { ranking }\end{array}$ & $\begin{array}{l}\text { Frequency } \\
\text { ranking }\end{array}$ & $\begin{array}{r}\text { Rescaled } \\
\text { utility score }\end{array}$ & $\begin{array}{l}\text { Best count } \\
\text { proportion }\end{array}$ & $\begin{array}{r}\text { Worst count } \\
\text { proportion }\end{array}$ \\
\hline GHG emissions & 1 & 1 & 14,3964 & 0,5750 & 0,0083 \\
\hline Raw material efficiency & 2 & 2 & 10,2738 & 0,3417 & 0,0417 \\
\hline End of life options & 3 & 3 & 10,0402 & 0,3500 & 0,0833 \\
\hline Ecotoxicity & 4 & 4 & 7,6652 & 0,2250 & 0,0250 \\
\hline Waste generation & 5 & 5 & 6,7041 & 0,2417 & 0,1000 \\
\hline Energy efficiency & 6 & 6 & 6,4310 & 0,1667 & 0,0750 \\
\hline Eutrophication & 7 & 9 & 5,9786 & 0,1917 & 0,0500 \\
\hline Natural land transformation & 8 & 7 & 5,4493 & 0,1833 & 0,1250 \\
\hline Agricultural land occupation & 9 & 8 & 5,3674 & 0,1750 & 0,1417 \\
\hline Abiotic fossil depletion & 10 & 10 & 5,2322 & 0,2000 & 0,1167 \\
\hline Organic carbon depletion & 11 & 12 & 4,9843 & 0,1667 & 0,0417 \\
\hline Water consumption & 12 & 11 & 3,9648 & 0,1083 & 0,1333 \\
\hline Management practices in crop production & 13 & 14 & 3,6921 & 0,1500 & 0,2583 \\
\hline Soil erosion & 14 & 13 & 2,9394 & 0,0667 & 0,1583 \\
\hline Acidification & 15 & 16 & 2,2364 & 0,0750 & 0,1917 \\
\hline Stratospheric ozone depletion & 16 & 18 & 1,5164 & 0,0667 & 0,3167 \\
\hline Particular matter formation & 17 & 17 & 1,3784 & 0,0167 & 0,2333 \\
\hline Abiotic mineral depletion & 18 & 15 & 1,2158 & 0,0333 & 0,2833 \\
\hline photo-oxidant formation & 19 & 19 & 0,3527 & 0,0000 & 0,3500 \\
\hline Ionising radiation & 20 & 20 & 0,1815 & 0,0000 & 0,6000 \\
\hline
\end{tabular}

Table 2. Best-Worst Scaling results for the environmental dimension

\begin{tabular}{lcccrrrr}
\hline Indicator & \multicolumn{3}{c}{ Hierarchical Bayes analysis } & & \multicolumn{2}{c}{ Counting analysis } \\
\cline { 2 - 3 } & $\begin{array}{r}\text { Average } \\
\text { ranking }\end{array}$ & $\begin{array}{c}\text { Frequency } \\
\text { ranking }\end{array}$ & $\begin{array}{r}\text { Rescaled } \\
\text { utility score }\end{array}$ & & $\begin{array}{r}\text { Best count } \\
\text { proportion }\end{array}$ & $\begin{array}{r}\text { Worst count } \\
\text { proportion }\end{array}$ \\
\hline Market potential & 1 & 1 & 18,4073 & & 0,4574 & 0,0233 \\
Raw materials cost & 2 & 2 & 15,5672 & & 0,3250 & 0,0333 \\
Process innovation & 3 & 4 & 8,9783 & & 0,2164 & 0,1194 \\
Product innovation & 4 & 3 & 8,6059 & & 0,1716 & 0,0672 \\
Energy cost & 5 & 5 & 8,6042 & & 0,1667 & 0,0333 \\
Technical Risks & 6 & 6 & 8,5811 & & 0,1825 & 0,0584 \\
Land productivity & 7 & 7 & 8,5131 & & 0,2417 & 0,1333 \\
Capital productivity & 8 & 8 & 8,1990 & & 0,1168 & 0,1241 \\
Product efficiency & 9 & 9 & 6,5183 & & 0,1085 & 0,1085 \\
Subsidies & 10 & 12 & 3,2001 & & 0,0949 & 0,4307 \\
Labor productivity & 11 & 11 & 1,6609 & & 0,0583 & 0,3167 \\
Transportation cost & 12 & 13 & 1,6474 & & 0,0310 & 0,4651 \\
Waste disposal cost & 13 & 10 & 1,5173 & 0,0149 & 0,2388 \\
\hline
\end{tabular}

Table 3. Best-Worst Scaling results for the economic dimension 


\begin{tabular}{|c|c|c|c|c|c|}
\hline \multirow[t]{2}{*}{ Indicator } & \multicolumn{3}{|c|}{ Hierarchical Bayes analysis } & \multicolumn{2}{|c|}{ Counting analysis } \\
\hline & $\begin{array}{l}\text { Average } \\
\text { ranking }\end{array}$ & $\begin{array}{l}\text { Frequency } \\
\text { ranking }\end{array}$ & $\begin{array}{r}\text { Rescaled } \\
\text { utility score }\end{array}$ & $\begin{array}{l}\text { Best count } \\
\text { proportion }\end{array}$ & $\begin{array}{c}\text { Worst count } \\
\text { proportion }\end{array}$ \\
\hline Human toxicity & 1 & 1 & 13,7164 & 0,3358 & 0,0373 \\
\hline Product transparency & 2 & 2 & 13,3042 & 0,3167 & 0,0833 \\
\hline Job creation & 3 & 3 & 12,2509 & 0,3723 & 0,1095 \\
\hline Acceptance of biobased materials & 4 & 4 & 11,8403 & 0,3798 & 0,1628 \\
\hline Fatal work injuries & 5 & 5 & 7,5035 & 0,2083 & 0,1500 \\
\hline Workplace accidents and illnesses & 6 & 6 & 6,6466 & 0,1240 & 0,0775 \\
\hline Community support and involvement & 7 & 7 & 6,3201 & 0,1866 & 0,1343 \\
\hline Income levels & 8 & 8 & 5,6892 & 0,0949 & 0,1241 \\
\hline Education and training & 9 & 9 & 4,8797 & 0,0930 & 0,1705 \\
\hline Child labor & 10 & 15 & 4,8053 & 0,0970 & 0,3284 \\
\hline Social security & 11 & 11 & 3,9995 & 0,0917 & 0,1833 \\
\hline Security measures & 12 & 10 & 3,8287 & 0,0917 & 0,2083 \\
\hline Discrimination & 13 & 12 & 2,3004 & 0,0511 & 0,1533 \\
\hline Working hours & 14 & 13 & 1,9336 & 0,0333 & 0,2500 \\
\hline Cultural heritage & 15 & 14 & 0,9817 & 0,0000 & 0,3500 \\
\hline
\end{tabular}

Table 4. Best-Worst Scaling results for the social dimension

In the third column, the HB frequency rankings (i.e. the second ranking method) are constructed based on the frequency an item was placed at a certain rank order. Individual rankings were created using the individual preference scores from the HB analysis. A first example is given in Figure 3, where a pairwise comparison is made between the frequencies of the attributes subsidies and transportation cost at a certain rank position. Although these frequency analyses give a good first impression of a final consensus ranking and avoids averaging, the distribution of some attributes can also be too dispersed for comparison. A second example, provided in Figure 3, shows the difficulty to compare the frequencies of four selected social indicators. To improve the validity of the final ranking, a model was created based on the HB AURORA method (i.e. the third ranking method) to construct a reliable consensus ranking.
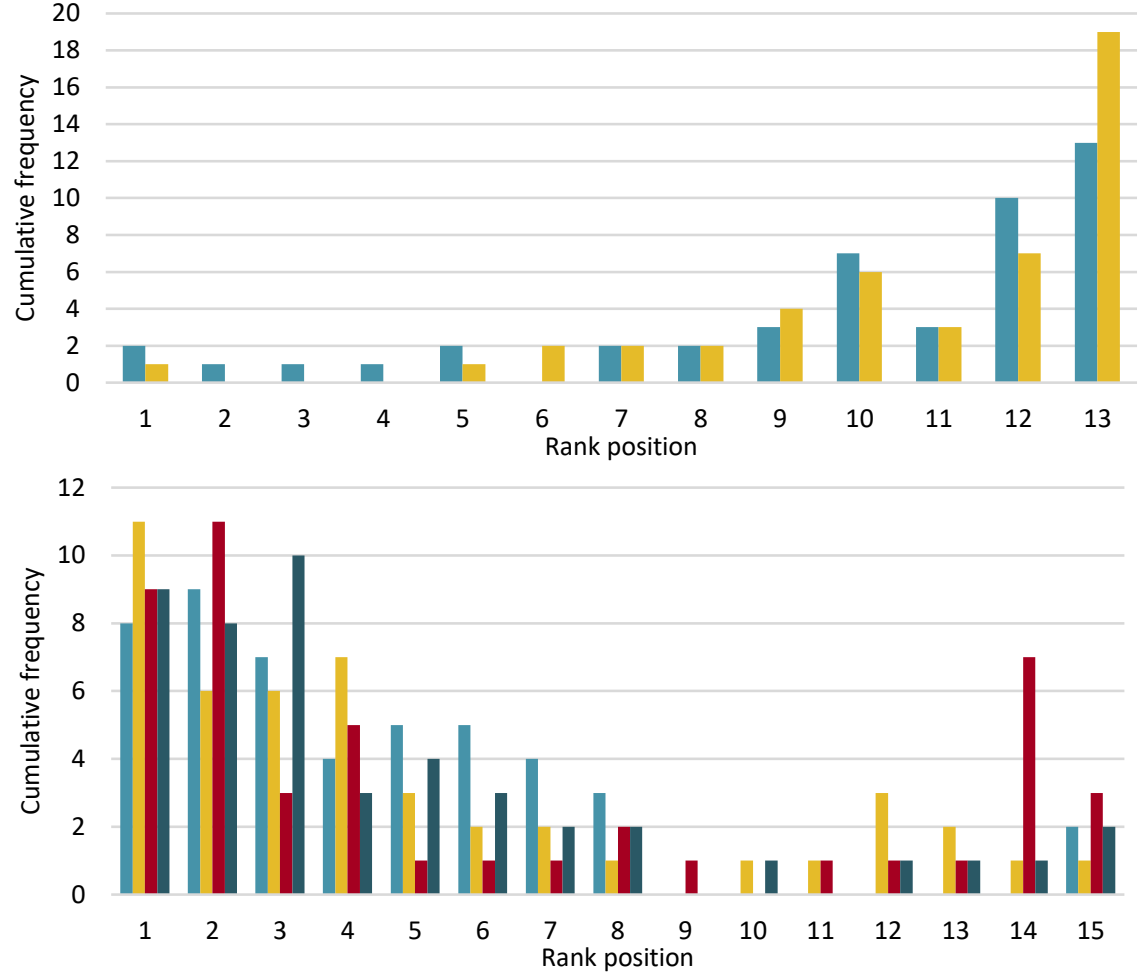

Figure 3. Cumulative frequencies of the rank positions
Subsidies

Transportation cost

- Human toxicity

Job creation

Acceptance of biobased materials

- Product transparency 
For the third ranking method, a Branch-and-Bound algorithm is written using the method of Springael and De Keyser (2009) to determine a prioritization of sustainability indicators per dimension (i.e. environment, economy and society). The median Kendall's $\tau$ is maximized to select the best fitting ranking. Multiple optimal solutions are found by running the Branch-and-Bound algorithm per sustainability dimension: 1 optimal solution for the environmental dimension, 23 optimal solutions for the economic dimension and 974 optimal solutions for the social dimension. An example is given in Figure 4, where the 23 solutions for the economic dimension are compared. Every optimal solution has the same maximized median Kendall's $\tau$, which is 0.6316 for the environmental sustainability solutions, 0.5641 for the economic sustainability solutions and 0.5048 for the social sustainability solutions. Intuitively, for the economic dimension, this means that at least $50 \%$ of the respondents have a rank correlation coefficient of 0.5641 or more with regard to the optimal solution.

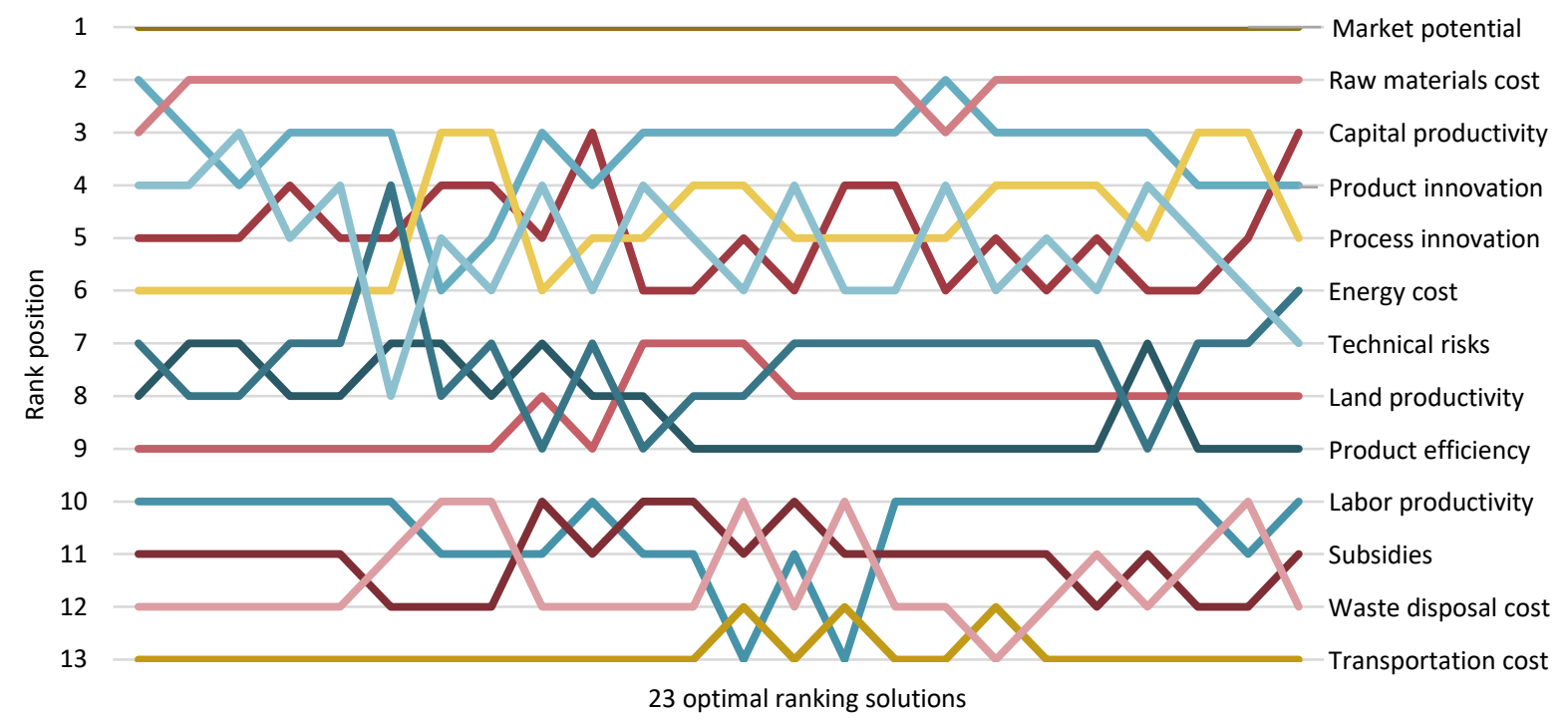

Figure 4. Optimal ranking solutions for the economic dimension (based on HB AURORA)

If the complexity of the decision problem increases, the AURORA algorithm generates a higher amount of optimal solutions with a lower median Kendall's $\tau$, designating a lack of consensus. Table 5 shows the corresponding rank correlation coefficients per decile. Decile 0 includes the decision maker with the lowest Kendall's $\tau$, i.e. the lowest agreement with the optimal solution. Decile 10 includes the decision maker with the highest Kendall's $\tau$, i.e. the highest agreement with the optimal solution. If consensus is compared between the three sustainability rankings, it is noted that there is relatively less consensus concerning social sustainability indicators, which is proven in this study by the high amount of optimal solutions (i.e. 974) and the relatively low median Kendall's $\tau$ (i.e. 0.5048). At least $10 \%$ of the decision makers have a negative correlation and tend to disagree with the optimal ranking solution. Social indicators are difficult to quantify and research is limited compared to economic and environmental assessment studies (Rafiaani et al., 2018). The root problems of social data scarcity and shortage of knowledge should be tackled to increase consensus and improve social sustainability analysis. The sole optimal environmental solution with a Kendall's $\tau$ of 0.6316 indicates that more attention in sustainability analysis is being paid to environmental indicators and experts tend to agree on the relative importance of these indicators.

\begin{tabular}{|c|c|c|c|c|c|c|c|c|c|c|c|}
\hline & \multicolumn{11}{|c|}{ Decile } \\
\hline & 0 & 1 & 2 & 3 & 4 & 5 & 6 & 7 & 8 & 9 & 10 \\
\hline Environment & 0,0842 & 0,2421 & 0,3158 & 0,4211 & 0,4947 & 0,6211 & 0,6421 & 0,6632 & 0,6842 & 0,7368 & 0,9158 \\
\hline Economy & $-0,1282$ & 0,2308 & 0,2564 & 0,3333 & 0,4615 & 0,5641 & 0,5897 & 0,6154 & 0,6667 & 0,7692 & 0,8205 \\
\hline Society & $-0,1619$ & $-0,0095$ & 0,1429 & 0,2190 & 0,2952 & 0,5048 & 0,5429 & 0,5619 & 0,6381 & 0,6762 & 0,7714 \\
\hline
\end{tabular}

Table 5. Kendall's $\tau$ per decile 
One optimal solution per sustainability dimension is selected based on a frequency analysis. The AURORA-based rankings, shown in Table 6 , are the best-fitting results considering a consensus has to be reached between all the experts. In the next section, the ranking positions of the different indicators will be further discussed.

\begin{tabular}{|c|c|c|c|c|c|}
\hline & Environment & & Economy & & Society \\
\hline 1 & GHG emissions & 1 & Market potential & 1 & Acceptance of biobased materials \\
\hline 2 & Raw material efficiency & 2 & Raw materials cost & 2 & Product transparency \\
\hline 3 & End of life options & 3 & Product innovation & 3 & Job creation \\
\hline 4 & Ecotoxicity & 4 & Process innovation & 4 & Human toxicity \\
\hline 5 & Waste generation & 5 & Technical risks & 5 & Income levels \\
\hline 6 & Energy efficiency & 6 & Capital productivity & 6 & Workplace accidents and illnesses \\
\hline 7 & Natural land transformation & 7 & Energy cost & 7 & Education and training \\
\hline 8 & Abiotic fossil depletion & 8 & Land productivity & 8 & Community support and involvement \\
\hline 9 & Eutrophication & 9 & Product efficiency & 9 & Fatal work injuries \\
\hline 10 & Agricultural land occupation & 10 & Labor productivity & 10 & Security measures \\
\hline 11 & Water consumption & 11 & Subsidies & 11 & Social security \\
\hline 12 & Organic carbon depletion & 12 & Waste disposal cost & 12 & Child labor \\
\hline 13 & Management practices & 13 & Transportation cost & 13 & Working hours \\
\hline 14 & Soil erosion & & & 14 & Discrimination \\
\hline 15 & Acidification & & & 15 & Cultural heritage \\
\hline 16 & Particular matter formation & & & & \\
\hline 17 & Abiotic mineral depletion & & & & \\
\hline 18 & Stratospheric ozone depletion & & & & \\
\hline 19 & Photo-oxidant formation & & & & \\
\hline 20 & Ionising radiation & & & & \\
\hline
\end{tabular}

Table 6. Final consensus rankings of sustainability indicators (based on HB AURORA)

\section{DISCUSSION}

The final results of the $\mathrm{HB}$ average ranking, $\mathrm{HB}$ frequency ranking and AURORA ranking, are discussed below based on literature and experts' feedback. GHG emissions is considered as the most relevant environmental indicator in all three ranking methods. Respondents indicate GHG emissions as a widely-accepted indicator with existing, elaborated calculation techniques. However, it is a common mistake to only include $G H G$ emissions and generalize these results to make conclusions about environmental sustainability. Second place in the environmental ranking is covered by raw material efficiency. In a time with growing scarcity of natural resources, the efficient use of raw materials is crucial for environmental as well as economic sustainability (European Commission, 2012; Mantau et al., 2010). Raw material efficiency is directly linked with the raw materials cost-indicator, also ranked second in the economic sustainability prioritization. End-of-life options are ranked third, including the options to recycle, biodegrade or, for example, using biobased waste streams for new products, which offers a solution for the competition with food and feed in the agricultural sector. Market potential is ranked first for economic sustainability, which considers product price and output. According to the experts, it gives a first indication if a product is viable compared to their fossil-based counterpart or other technologies and feedstocks. For the societal domain, the top 4 indicators are ranked in a different order when comparing the three ranking methods. Human toxicity takes the lead when using the HB average- and frequency method, but gets ranked fourth when applying the HB AURORAmethod. Within the chemical sector 'toxicity' is considered an important topic considering many chemicals are hazardous to human health and/or the environment (Eurostat, 2017b). Product transparency, ranked second when applying HB AURORA, is highly related with the communication strategy towards the customers. Disclosing detailed product information avoids greenwashing and builds trust, leading to potential economic advantages in the long run. Finally, Acceptance of biobased materials is placed first in the HB AURORA ranking. Public acceptability can pose a major barrier 
towards new innovative products. The measurement of social acceptance is difficult to define as it relates to many subjective and qualitative aspects. Social acceptance can be defined by sub-indicators like fear, knowledge and perception (Assefa and Frostell, 2007). Nevertheless, measurement methods are limited and no case studies where found focusing on the acceptance of biobased chemicals (Van Schoubroeck et al., 2018).

Next to the top ranked indicators, it is also valuable to examine the indicators ranked at the bottom. Although respondents selected social sustainability indicators related to working conditions as relevant in the first Delphi round, an explanation given to the relatively low ranking position of child labor, security measures and working hours is the stringent social regulation in Europe. For example, child labor is completely banned in the European Union and might not be relevant to assess in social sustainability analysis when the entire value chain is EU based. The same argumentation is used with the valuation of the indicator photo-oxidant formation, better known as 'summer smog', which is perceived by the experts to be a more urgent matter in the metropolitan areas in Asia. However, sustainability assessment is very case specific and this general prioritization of the indicators does not mean that the attributes ranked low are not relevant in some specific biobased chemical processes. For example, although ionising radiation is ranked last in Table 6, it can be a crucial sustainability indicator in certain processes using radioactive materials.

In the following paragraphs, some limitations, challenges and ideas for future research are discussed. First, some methodological concerns are raised. This Delphi study uses Best-Worst Scaling which avoids scaling bias and provokes discrimination (Flynn and Marley, 2014). To avoid lengthy questions, the description of the indicators in the questionnaire is brief and to the point, which is in strong contrast with the complex nature of the research question. In some cases, this might lead to ambiguous questions and misinterpretation of the different sustainability attributes. For that reason, definitions are provided at the start of the survey and a 'comment box' is included in both rounds to encourage respondents to report haziness. A follow-up focus group could improve the validity of the research and gather information for the application of the selected sustainability indicators on a European case study (Morgan and Krueger, 1993).

Furthermore, the three ranking methods used in this study (i.e. HB average ranking, HB frequency ranking and HB AURORA ranking) show large similarities within the rankings, which indicates robustness in the survey results. The top and bottom ranked indicators remain stable and only minor switches between the indicators appear when changing the ranking method. In this study, the Branchand-Bound algorithm of the AURORA method does not allow for ties. Such a constraint in the model ensures a clear-cut ranking for decision makers who have to perform assessment with a limited amount of resources. However, allowing for ties could potentially increase consensus and enable clustering of the indicators. Future research could extend the current AURORA algorithm and investigate the effects of allowing ties into the MCDA model (De Keyser and Springael, 2009)

Apart from methodological challenges, follow-up research is necessary to apply and verify the indicators for biobased chemical assessment. Current sustainability evaluations lack an inclusion of social aspects or tend to focus only on human toxicity (Van Schoubroeck et al., 2018). To perform a balanced sustainability analysis, the development of measurement methods for social indicators like acceptance of biobased materials and product transparency are necessary to fill the gap in current literature. Next, the indicators identified by this Delphi study are broadly defined and might include sub-indicators and be quantified in many ways. For example, eutrophication can be divided in marine water, freshwater or terrestrial eutrophication. These subdivisions create more insights and better judgement of sustainability. The performance of a case study can identify the further need for subdivisions and relevant sub-indicators. In addition, when using this prioritized set of sustainability indicators in practice, the challenge remains to include the linkages and interdependencies between 
the different sustainability indicators and domains. By incorporating the interrelationships between environment, society and economy, the tradeoffs and win-wins can be discovered (Hacking and Guthrie, 2008).

Finally, this study develops a general indicator prioritization for European biobased chemicals, but a complete sustainability analysis should include as much information as possible. A prioritization can be useful when resources are limited for example when data is lacking due to a low TRL or projects in small and medium-sized enterprises (SME's). In order to adapt this general prioritization to a specific case, an iterative stakeholder process is suggested. Experts should first assess the general guideline and propose changes to confirm all the crucial indicators are included in the analysis. After a first round of indicator calculations on the specific case study, stakeholders are consulted again to evaluate the validity and completeness of the first results. The developed, general rankings in this study provide a foundation for further harmonization between practitioners of sustainability analysis, focusing on the research field of biobased chemicals.

\section{CONCLUSION}

A two-round Delphi study using Best-Worst Scaling exercises resulted in consensus rankings of sustainability indicators, specifically developed for biobased chemicals. The expert elicitation process was performed with stakeholders from the private, public and academic sector. The final rankings represent how experts elaborate on the concept of sustainability within biobased chemistry and offers a prioritization of indicators to practitioners of sustainability analysis within Europe. Three different kind of methods were used to develop a ranking of the sustainability attributes: (1) Hierarchical Bayes average ranking, (2) Hierarchical Bayes frequency ranking and (3) Hierarchical Bayes AURORA ranking. The different methodologies and outcomes are compared and the third, MCDA, method is chosen as the most appropriate ranking method, using a Branch-and-Bound algorithm to reach expert consensus. Consensus is measured by the median Kendall's $\tau$ and proves to be positive within all three sustainability domains. The strongest consensus is measured for the environmental sustainability ranking with a median Kendall's $\tau$ of 0.6316 . The weakest consensus was found for the social sustainability ranking with a median Kendall's $\tau$ of 0.5048 .

The experts indicate GHG emissions, market potential and acceptance of biobased materials as the most crucial indicators for environmental, economic and social sustainability. In literature, a significant lack of societal aspects is noticed within sustainability analysis of biobased chemicals. By using the results of the MCDA performed in this study, priorities can be established for the inclusion and measurement of social aspects. Furthermore, a prioritization of indicators is useful to assign weights or select attributes when resources like time, data and money are limited or unavailable. However, reducing the amount of indicators is always a risk and makes the analysis less comprehensive and complete. Key in performing sustainability analysis is being transparent about the indicator specifications and limitations of the study. Experts therefore prefer multiple sustainability indicators over one single index.

Finally, these ranked sets of sustainability indicators provide general guidelines for indicator selection in biobased chemistry, but the relevance of different (sub)indicators might differ from case to case. Future research should apply the indicators on specific case studies in order to verify and extend a full sustainability analysis. Assessing sustainability of biobased chemicals is an essential step towards a sustainable biobased economy with environmental, economic and societal benefits over product life cycles. 


\section{ACKNOWLEDGEMENTS}

We would like to thank the Noun Project for contributing to the graphical abstract by designing and providing the necessary icons.

\section{REFERENCES}

Assefa, G., Frostell, B., 2007. Social sustainability and social acceptance in technology assessment: A case study of energy technologies. Technol. Soc. 29, 63-78. https://doi.org/10.1016/j.techsoc.2006.10.007

Bana e Costa, C.A., Chagas, M.P., 2004. A career choice problem: An example of how to use MACBETH to build a quantitative value model based on qualitative value judgments. Eur. J. Oper. Res. 153, 323-331. https://doi.org/10.1016/S0377-2217(03)00155-3

Benitez-Capistros, F., Hugé, J., Koedam, N., 2014. Environmental impacts on the Galapagos Islands: Identification of interactions, perceptions and steps ahead. Ecol. Indic. 38, 113-123. https://doi.org/10.1016/j.ecolind.2013.10.019

Bennich, T., Belyazid, S., 2017. The route to sustainability-prospects and challenges of the bio-based economy. Sustainability 9, 1-18. https://doi.org/10.3390/su9060887

Carter, N., 2018. The politics of the Environment: Ideas, Activism, Policy. Cambridge University Press.

Chang, P.T., Huang, L.C., Lin, H.J., 2000. The fuzzy Delphi method via fuzzy statistics and membership function fitting and an application to the human resources. Fuzzy Sets Syst. 112, 511-520. https://doi.org/10.1016/S0165-0114(98)00067-0

Chiu, A., Ashton, W., Moreau, V., Tseng, M., 2018. Sustainable Management of Natural Resources toward Sustainable Development Goals. Resour. Conserv. Recycl. 136, 335-336. https://doi.org/10.1016/j.resconrec.2018.04.019

De Carvalho, B.E., Marques, R.C., Netto, O.C., 2017. Delphi technique as a consultation method in regulatory impact assessment (RIA) - The Portuguese water sector. Water Policy 19, 423-439. https://doi.org/10.2166/wp.2017.131

De Feo, G., De Gisi, S., De Vita, S., Notarnicola, M., 2018. Sustainability assessment of alternative enduses for disused areas based on multi-criteria decision-making method. Sci. Total Environ. 631632, 142-152. https://doi.org/10.1016/j.scitotenv.2018.03.016

De Keyser, W., Springael, J., 2009. Why don't we kiss!? University Press Antwerp.

European Commission, 2012. Innovating for Sustainable Growth: A bioeconomy for Europe. Brussels. European Committee for standardization, 2014. European Standard EN 16575 "bio-based products Vocabulary."

Eurostat, 2017a. Energy, transport and environment indicators | 2017 Edition, 2017th ed, Eurostat Pocketbook. https://doi.org/10.2785/964100 KS-DK-17-001-EN-N

Eurostat, 2017b. [dataset] Production and consumption of chemicals by hazard class.

Finn, A., Louviere, J.J., 1992. Determining the appropriate response to evidence of public concern: The case of food safety. J. Public Policy Mark. 11, 12-25. https://doi.org/10.2307/30000270

Flynn, T.N., Marley, A.A.J., 2014. Best worst scaling: Theory and methods, in: Handbook of Choice Modelling. Edward Elgar Publishing, pp. 178-201. https://doi.org/10.1017/CBO9781107337855.010

Fritsche, U.R., Iriarte, L., 2014. Sustainability criteria and indicators for the bio-based economy in Europe: State of discussion and way forward. Energies 7, 6825-6836. https://doi.org/10.3390/en7116825

Gawel, E., Ludwig, G., 2011. The iLUC dilemma: How to deal with indirect land use changes when governing energy crops? Land use policy 28, 846-856. https://doi.org/10.1016/j.landusepol.2011.03.003

Hacking, T., Guthrie, P., 2008. A framework for clarifying the meaning of Triple Bottom-Line, Integrated, and Sustainability Assessment. Environ. Impact Assess. Rev. 28, 73-89. https://doi.org/10.1016/j.eiar.2007.03.002 
Hai, L.T., Hai, P.H., Ha, P.T.T., Ha, N.M., Dai, L.T., Hoa, P.V., Huan, N.C., Cam, L.V., 2014. A System of Sustainability Indicators for the Province of Thai Binh, Vietnam. Soc. Indic. Res. 116, 661-679. https://doi.org/10.1007/s11205-013-0315-x

Hasson, F., Keeney, S., McKenna, H., 2000. Research guidelines for the Delphi survey technique. J. Adv. Nurs. 32, 1008-1015. https://doi.org/10.1046/j.1365-2648.2000.t01-1-01567.x

Hoogmartens, R., Van Passel, S., Van Acker, K., Dubois, M., 2014. Bridging the gap between LCA, LCC and CBA as sustainability assessment tools. Environ. Impact Assess. Rev. 48, 27-33. https://doi.org/10.1016/j.eiar.2014.05.001

Jong, E. de, Higson, A., Walsh, P., Wellisch, M., 2011. Task 42 Biobased Chemicals - Value Added Products from Biorefineries. A Rep. Prep. IEA Bioenergy-Task 34. https://doi.org/10.1126/science.1179713

Kendall, M.G., 1970. Rank correlation methods, 4th ed. London.

Kendall, M.G., 1938. A New Measure of Rank Correlation. Biometrika 30, 81-89. https://doi.org/10.2307/2332226

Keune, H., Springael, J., Keyser, W. De, 2013. Negotiated Complexity: Framing Multi-Criteria Decision Support in Environmental Health Practice. Am. J. Oper. Res. 3, 153-166. https://doi.org/10.4236/ajor.2013.31A015

Lee, J.A., Soutar, G., Louviere, J., 2008. The best-worst scaling approach: An alternative to Schwartz's values survey. J. Pers. Assess. 90, 335-347. https://doi.org/10.1080/00223890802107925

Mantau, U., Saal, U., Prins, K., Steierer, F., Lindner, M., Verkerk, H., Eggers, J., Leek, N., Oldenburger, J., Asikainen, A., Anttila, P., 2010. EUwood- Real Potential for Changes in Growth and Use of Forests. Final Report. Hamburg.

Mapar, M., Jafari, M.J., Mansouri, N., Arjmandi, R., Azizinejad, R., Ramos, T.B., 2017. Sustainability indicators for municipalities of megacities: Integrating health, safety and environmental performance. Ecol. Indic. 83, 271-291. https://doi.org/10.1016/j.ecolind.2017.08.012

Morgan, D.L., Krueger, R.A., 1993. When to use focus groups and why, in: Successful Focus Groups: Advancing the State of the Art. SAGE Publications, Inc., 2455 Teller Road, Thousand Oaks California 91320 United States. https://doi.org/10.4135/9781483349008

NVivo, 2015. NVivo Qualitative data analysis Software. QSR International Pty Ltd.

Okoli, C., Pawlowski, S.D., 2004. The Delphi method as a research tool: an example, design considerations and applications. Inf. Manag. 42, 15-29. https://doi.org/10.1016/j.im.2003.11.002

Orme, B.K., Baker, G.C., 2000. Comparing Hierarchical Bayes Draws and Randomized First Choice for Conjoint Simulations. Sawtooth Softw. Res. Pap. Ser.

Philp, J., 2017. The bioeconomy, the challenge of the century for policy makers. N. Biotechnol. 40, 1119. https://doi.org/10.1016/j.nbt.2017.04.004

Philp, J.C., Ritchie, R.J., Allan, J.E.M., 2013. Biobased chemicals: The convergence of green chemistry with industrial biotechnology. Trends Biotechnol. 31, 219-222. https://doi.org/10.1016/j.tibtech.2012.12.007

Pursula, T., Aho, M., Rönnlund, I., Päällysaho, M., 2018. Towards a Sustainable Bioeconomy: Principles, Challenges and Perspectives, Environmental Sustainability Indicators for the Bioeconomy, World Sustainability Series. Springer International Publishing, Cham. https://doi.org/10.1007/978-3319-73028-8

Rafiaani, P., Kuppens, T., Dael, M. Van, Azadi, H., Lebailly, P., Passel, S. Van, 2018. Social sustainability assessments in the biobased economy: Towards a systemic approach. Renew. Sustain. Energy Rev. 82, 1839-1853. https://doi.org/10.1016/j.rser.2017.06.118

Ranta, V., Aarikka-Stenroos, L., Ritala, P., Mäkinen, S.J., 2018. Exploring institutional drivers and barriers of the circular economy: A cross-regional comparison of China, the US, and Europe. Resour. Conserv. Recycl. 135, 70-82. https://doi.org/10.1016/j.resconrec.2017.08.017

Ronzon, T., Piotrowski, S., M'Barek, R., Carus, M., 2017. A systematic approach to understanding and quantifying the EU's bioeconomy. Bio-based Appl. Econ. 6, 1-17. https://doi.org/10.13128/BAE- 
20567

Roy, B., Vincke, P., 1981. Multicriteria analysis : survey and new directions. Eur. J. Oper. Res. 8, 207218. https://doi.org/https://doi.org/10.1016/0377-2217(81)90168-5

Saaty, T.L., Ozdemir, M.S., 2003. Why the magic number seven plus or minus two. Math. Comput. Model. 38, 233-244. https://doi.org/10.1016/S0895-7177(03)90083-5

Sawtooth Software, 2013. The MaxDiff System Technical Paper. Sawtooth Softw. Tech. Pap. Ser.

Sawtooth Software, 2009. The CBC / HB System for Hierarchical Bayes Estimation Version 5.0 Technical Paper. Sawtooth Softw. Tech. Pap. Ser.

Sheldon, R.A., 2011. Utilisation of biomass for sustainable fuels and chemicals: Molecules, methods and metrics. Catal. Today 167, 3-13. https://doi.org/10.1016/j.cattod.2010.10.100

Strauss, A., Corbin, J.M., 1998. Open coding, in: Basics of Qualitative Research: Techniques and Procedures for Developing Grounded Theory. Sage, Thousand Oaks, pp. 101-121. https://doi.org/10.4135/9781412957397.n342

Thomassen, G., 2018. The development of an integrated environmental techno-economic assessment framework. How to assess the potential of microalgal-based biorefineries? Hasselt University.

Trump, B., Cummings, C., Kuzma, J., Linkov, I., 2018. A decision analytic model to guide early-stage government regulatory action: Applications for synthetic biology. Regul. Gov. 12, 88-100. https://doi.org/10.1111/rego.12142

Trump, B.D., Kadenic, M., Linkov, I., Trump, B.D., Kadenic, M., Linkov, I., 2018. A sustainable Arctic : Making hard decisions A sustainable Arctic : Making hard decisions. Arctic, Antarct. Alp. Res. 50, 1-10. https://doi.org/10.1080/15230430.2018.1438345

Van Schoubroeck, S., Van Dael, M., Van Passel, S., Malina, R., 2018. A review of sustainability indicators for biobased chemicals. Renew. Sustain. Energy Rev. 94, 115-126. https://doi.org/10.1016/j.rser.2018.06.007

World Commission on Environment and Development, 1987. Our Common Future ('Brundtland report'), Oxford University Press.

Wu, W., Long, M., Zhang, X., Reed, J., Maravelias, C., 2018. A framework for the identification of promising bio-based chemicals. Biotechnol. Bioeng. https://doi.org/10.1002/bit.26779

Zhao, H., Li, N., 2016. Optimal siting of charging stations for electric vehicles based on fuzzy Delphi and hybrid multi-criteria decision making approaches from an extended sustainability perspective. Energies 9. https://doi.org/10.3390/en9040270 
Appendix A. Pseudocode Branch-and-Bound algorithm

Start

Initialize

Start

Set to investigate := Set of all solutions

Best bound for median $\tau$ found until now $:=-1$

Bound for median $\tau:=1$

Set of optimal solutions : $=\varnothing$

End

Repeat

Set to investigate := Branch with highest bound for median $\tau$ and most alternatives ranked $i:=$ number of alternatives ranked in chosen branch

If $\mathrm{i}<\mathrm{n}$ then

$\mathrm{i}:=\mathrm{i}+1$

Expand the branch by adding i subbranches

Foreach subbranch do

Calculate corresponding bound

If bound for median $\tau<$ best bound for median $\tau$ found until now then

Remove this branch

End if

End foreach

Else if bound for median $\tau>$ best bound for median $\tau$ found until now then

Best bound for median $\tau$ found until now := bound for median $\tau$

Set of optimal solutions := \{branch $\}$

Else if bound for median $\tau=$ best bound for median $\tau$ found until now then

Set of optimal solutions := Set of optimal solutions $U$ \{branch $\}$

End if

Until Set to investigate $=\varnothing$

End 


\section{INDICATOR}

Abiotic fossil depletion

Abiotic mineral depletion

Acidification

Agricultural land occupation

Ecotoxicity

End of life options

Energy efficiency

Eutrophication

GHG emissions

lonising radiation

Management practices in crop production

$\sum_{u}$ Natural land transformation

Organic carbon depletion

Particular matter formation

photo-oxidant formation

Raw material efficiency

Soil erosion

Stratospheric ozone depletion

Waste generation

\section{Capital productivity}

Energy cost

Labor productivity

Land productivity

$\succ \quad$ Market potential

Process innovation

Product efficiency

Raw materials cost

Subsidies

Technical risks

Transportation cost

Waste disposal cost

\section{DESCRIPTION}

Fossil resources required to produce a biobased chemical

Mineral resources required to produce a biobased chemical

Emissions causing acidifying effects to the environment

Amount of agricultural area occupied

Emissions of toxic substances to air, water and soil

Possibilities for recycling, composting, biodegrading, burning, ... the end product

Amount of energy from renewable and non-renewable resources needed per biobased chemical

Emissions (including phosphor and nitrogen) that cause eutrophication of marine water, fresh water and terrestrial environment

Greenhouse gas emissions and their contribution to climate change (including biogenic carbon and direct and indirect land use change)

Level of exposure related to releases of radioactive material to the environment

The type of practices used for crop production

Amount of transformed 'natural land' area (=no human distortion)

Amount of organic carbon in the soil lost

Presence of PM10 in the air

Formation of summer smog

Amount of raw materials needed per biobased chemical

Displacement of the upper layer of the soil

Emissions causing depletion of the ozone layer

Amount and type of waste generated (e.g. by calculating 'atom economy')

Capital needed for the production per biobased chemical

Cost of energy per biobased chemical

Direct and indirect labor needed for the production per biobased chemical

Direct land needed for the production per biobased chemical

Market price and size per biobased chemical

Effects on price and output of improvement of facilities, skills and technologies, etc.

Actual productivity divided by maximum productivity

Effects on price and output of new products, new features, improvement of performance, etc.

Cost of feedstock per biobased chemical

Amount of subsidies per biobased chemical

Risks associated directly with the supply chain activities, e.g. feedstock supply risk, infrastructure risk, etc.

Cost of transportation per biobased chemical

Cost of waste disposal per biobased chemical 
Acceptance of biobased chemicals

Child labor

Community support and involvement

Cultural heritage

Discrimination

Education and training

Fatal work injuries

Human toxicity

Income levels

Job creation

Product transparency

Security measures

Social security

Working hours

Workplace accidents and illnesses

\section{Perception of consumers towards the biobased chemical}

Presence of child labor

Support and involvement from the local community

Respect towards local cultural heritage (including language, religion, etc.)

A "fair chance" for everybody, e.g. equal payment male/female

Education and training initiatives and opportunities

Number of fatal work injuries

Effects of toxic substances on the human environment

Level of income of the workers

Number of jobs created

Creation of an informed choice for the consumer without intent to mislead or conceal

Security measures taken at the workplace

Compensation for retirement, disability, illness, injury, etc.

Number of hours worked

Number of workplace accidents and illnesses 


\section{Appendix C. Rankings per sustainability dimension (based on HB utility scores)}

5

6

7

8
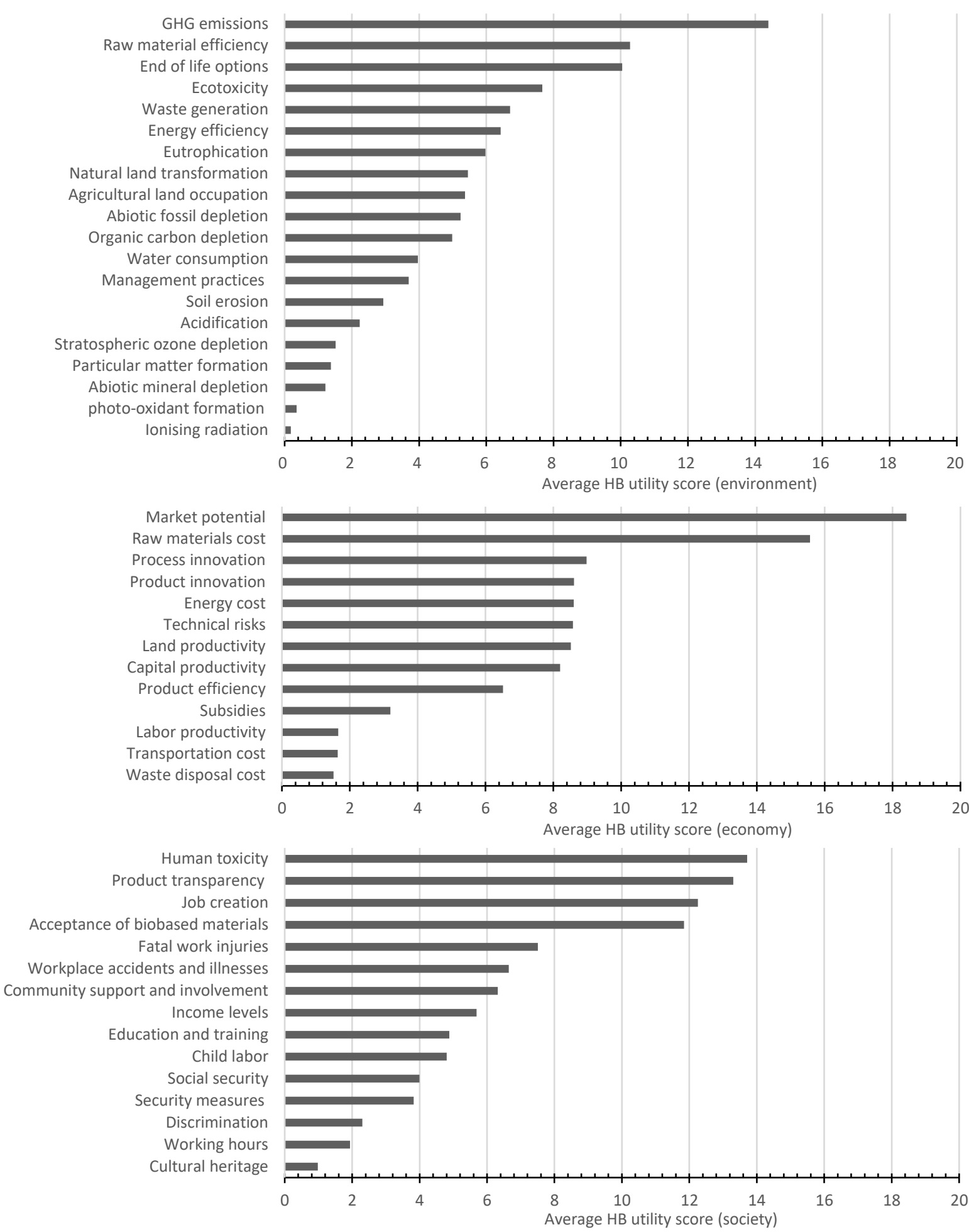